\title{
Ventilator associated pneumonia and transfusion, is there really an association? (the NAVTRA study)
}

\author{
David Yepes*1, Bladimir Gil2, Olga Hernandez ${ }^{3}$, Rodrigo Murillo ${ }^{4}$, \\ Marco Gonzalez ${ }^{5}$ and Juan Pablo Velasquez ${ }^{6}$
}

Address: ${ }^{1}$ Department of critical care, Clinica Universitaria Bolivariana and Clinica CES, Department of epidemiology, University CES, Medellín, Colombia, ${ }^{2}$ Department of critical care, Clínica Las Américas, Clínica Medellín, Grupo de Investigación en Cuidado Crítico, Universidad Pontificia Bolivariana, Department of epidemiology, University CES, Medellín, Colombia, ${ }^{3}$ Department of critical care, Clinica Medellín, Medellín, Colombia, ${ }^{4}$ Department of critical care, Clinica Medellin, Hospital Pablo Tobon Uribe, Grupo de Investigacion en cuidado critico, Universidad Pontificia Bolivariana, Medellín, Colombia, ${ }^{5}$ Department of critical care, Clinica Medellín, Grupo de Investigacion en cuidado critico, Universidad Pontificia Bolivariana, Medellín, Colombia and ' ${ }^{2}$ Division medical and critical care medicine, Surgical Critical Care unit, University Nueva Granada, Hospital Militar, Bogota, Colombia

Email: David Yepes* - dyepesmx@yahoo.com.mx; Bladimir Gil - bladigil@yahoo.com; Olga Hernandez - olguitahdez@hotmail.com; Rodrigo Murillo - ucimurillo@yahoo.com; Marco Gonzalez - mga@une.net.co; Juan Pablo Velasquez - juanpablocrip@gmail.com

* Corresponding author

Published: 25 July 2006

BMC Pulmonary Medicine 2006, 6:18 doi:10.1186/147I-2466-6-18

This article is available from: http://www.biomedcentral.com/I47/-2466/6/18

(C) 2006 Yepes et al; licensee BioMed Central Ltd.

This is an Open Access article distributed under the terms of the Creative Commons Attribution License (http://creativecommons.org/licenses/by/2.0), which permits unrestricted use, distribution, and reproduction in any medium, provided the original work is properly cited.

\section{Abstract}

Background: Anemic syndrome is a frequent problem in intensive care units. The most probable etiology is the suppression of the erythropoietin response due to the direct effects of cytokines, as well as frequent blood sampling.

Transfusions are not free of complications, therefore transfusion reactions are estimated to occur in $2 \%$ of the total packed red blood cells (PRBCs) transfused.

In the past several years, several trials had tried to compare the restrictive with the more liberal use of transfusions, and they were found to be equally effective.

Nosocomial pneumonia is the most common nosocomial infection in intensive care units; the prevalence is $47 \%$ with an attributive mortality of $33 \%$.

There are multiple risk factors for the development of nosocomial pneumonia. Colonization of the upper airways is the most important pathophysiological factor but there are other factors implicated like, sedation techniques, inappropriate use of antibiotics and recumbent positioning.

A secondary analysis of the CRIT study describes transfusion therapy and its practices in the United States. They found that transfusion practice is an independent risk factor for the development of nosocomial pneumonia.

Methods: This is a multicenter, prospective cohort study in different intensive care units in Colombia. A total of $\mathbf{4 7 4}$ patients were selected who had more than 48 hours of mechanical ventilation.

The primary objective is to try to demonstrate the hypothetical relationship between the use of transfusions and nosocomial pneumonia. 
Secondly, we will try to determine which other factors are implicated in the development of pneumonia in intensive care units and describe the incidence of pneumonia and transfusion practices.

Discussion: Ventilator associated pneumonia is a primary problem in the intensive care unit, multiple factors have been associated with its presence in this study we try to explore the possible association between pneumonia and transfusion, describe all other factors associated with this, and the possible association with other nosocomial infections.

\section{Background}

Anemia is a frequent problem in intensive care units. The most probable etiology is the suppression of the erythropoietin response due to the direct effects of cytokines, as well as frequent blood sampling [1].

In the United States it is estimated that 3,500 transfusions are given daily, around 1.25 million transfusions throughout the year, and $73 \%$ of patients that stay in an intensive care unit for more than 7 days are transfused [2], with pretransfusion average hemoglobin of $8.4 \mathrm{~g} / \mathrm{dL}$

One of the most alarming risks of anemia is lost of capacity to transport oxygen. Nevertheless, animal studies have found tolerance levels of hemoglobin as low as $3 \mathrm{~g} / \mathrm{dL}$, as well as a good tolerance of hemodilution, electrocardiographic changes and ventricular function, at these levels $[3,4]$.

Elderly patients with coronary artery disease, cerebrovascular disease and pulmonary disease are groups considered intolerant to important decreases in the levels of hemoglobin. A common use of transfusion practice in hospitalized patients is to maintain hemoglobin levels within normal limits. However, there is no evidence that confirms these findings [5].

Transfusion practice involves multiple health risk due to its inadequate use. Adverse effects are frequent and can present in up to $2 \%$ of transfusions including infrequent diseases as hepatitis C and HIV [6] as well as immunemediated reactions, with an incidence of 1 in 1.000.000 fatal hemolytic reactions [7]. Other more commonly seen are fluid overload along with noninfectious complications such as non- hemolytic, febrile reactions as well as allergic reactions.

TRALI is a non-cardiogenic type of pulmonary edema associated with transfusions, classified as a serious complication, which has been the cause of 45 deaths within 1992 - 2002. Its pathogenesis is the entrapping of leukocytes in the pulmonary microcirculation with an increase in pulmonary permeability [8]. Immunomodulationassociated transfusion which was used in the past to improve survival in transplanted patients has not been systematically studied. An association between the recurrence of cancer, the presence of nosocomial infections and the use of transfusions has been reported [9]. There is evidence that stored leukocytes found in a unit of blood could produce cytokines that interfere with the immune function. A transfusion introduces new antigens as Histocompatibility antigens (HLA) which interact with native T-cells as well as molecules called co stimulators that can cause a suppression of immune response [10].

Microquimerism has been proposed as another mechanism of immunomodulation-associated transfusions. Although, HLA compatibility between donor and receiver can result in the persistence of leukocytes from the donor and antigen presenting cells causing a decrease immune response and a tolerance to the antigens from the donor. Microquimerism results in the release of IL -4 , IL - 10 and transforming growth $\beta$ factor; cytokines that inhibit the production of other inflammatory molecules. The loss of immunogenicity by transfused leukocytes results in anergy from T cells as well as immunosupression [11].

Different studies have reported the association between transfusions and nosocomial infection $[9,12,13]$. The immunomodulation generated by transfusions is a factor associated with the presence of intrahospital infections which has a great impact on mortality and costs generated from intensive care units.

Ventilator associated pneumonia (VAP) is the most common infection found in intensive care units (ICU's), with a prevalence of $47 \%$ of total infections in ICU[14]; $25 \%$ of all nosocomial infections, with an estimated 5 to 10 VAP cases per 1000 hospital admissions and $9-27 \%$ of intubated patients with an attributable mortality of $33 \%$ $[15,16]$. In addition, VAP contributes to increase morbidity due to length of stay on mechanical ventilation and hospital stay $[16,17]$, and increasing hospital costs $[18,19]$. In the United States, VAP can cost approximately 40,000 dollars per case, presenting 300,000 new cases annually. Therefore, the amounts of resources used for treatment are huge; placing efforts to prevent this pathology. The main risk factor for VAP is the length of stay on mechanical ventilation increasing colonization of upper airways and stomach by pathogenic germs, further predis- 
posing to micro aspiration which seems to be the pathophysiology for VAP [20]. Stomach colonization by pathogenic germs as a source of pneumonia is related to multiple factors such as an inadequate use of antibiotics, prophylaxis use for stress ulcers, supine position, severity of disease including hemodinamic instability and use of vasopressors; the use of continuous sedation as well as parenteral nutrition. Recognizing the risk factors might enable us to establish suitable measures for the prevention and management of VAP.

$44 \%$ of the patients received one or more units of packed red blood cells during their stay in the ICU [21], these transfusions have been associated with the disruption of the immune response in the receptor $[22,23]$ and related to the presence of severe nosocomial infections other than VAP [9,24-26]. Recently, one analysis of transfusion practice in the United States found an association between the transfusion and VAP [13]. However, no studies have been done to try and find an association between transfusions and VAP as a primary endpoint. Different trials that have found an association between nosocomial infection and transfusions were retrospective and other results came from secondary analysis or from transfusion practices. At this moment, evidence support that conservative transfusion practice in critically ill patients is as effective as the liberal strategies in terms of morbidity and mortality [27]. Unfortunately, we do not know if these practices are presently done in our ICU's. As previously stated, we consider that this study is very important and necessary to answer if there is truly a correlation between VAP and use of transfusions as well as to know the transfusion practices in our institutions. With this present study, we want to confirm the association between red blood cell transfusions and VAP as a primary endpoint. Also, identify the incidence of VAP in our ICU's establishing its characteristics, total mortality, mortality attributed to VAP and length of ICU stay as a secondary endpoint. Our theory is that if an association is found, then it is possible that by decreasing the frequency of transfusions this will decrease the incidence of VAP as well as mortality.

\section{Methods \\ Objectives}

\section{Primary objective}

1. Establish the association between transfusion of packed red blood cells (pRBCs) and Ventilator associated pneumonia (VAP).

\section{Secondary objective}

1. Describe the demographic variables in both groups.

2. Establish the incidence of VAP in both groups.

3. Establish current transfusion practices in ICU.
4. Establish the main risk factors associated with the onset of VAP in our population.

5. Estimate the incidence of anemia in patients on mechanical ventilation.

6. Describe the complications related to transfusions in our study.

\section{Hypothesis \\ Null hypothesis}

Patients on mechanical ventilation who are transfused with packed red blood cells present an incidence of NAV equal to patients who are not transfused during the stay in ICU.

\section{Proposed methodology \\ Type of study}

This is a prospective, multicenter, cohort study.

In the design of the study the comparison between both groups was made with a proportion of 1:1, the disparity reason of presenting VAP in patients with mechanical ventilation who were transfused is 1.89 [13] and the prevalence of VAP in the ICU is an average of $18 \%$ [16]. The sample size calculated based on the reason of disparity of the exposed group and the prevalence of the disease in the group not exposed, with an error alpha of a 0,05 and power of 0.8 , the number of people that is required is of 237 patients in each arm (total of 474) to two tails. To calculate the sample we are going to use the program EpiInfo for cohort studies [28].

\section{Inclusion criteria}

Patients with mechanical ventilation for more than 48 hours

\section{Exclusion criteria}

-Younger than 18 years old.

-Pregnancy.

-Patients with contraindications for transfusion of packed red blood cells.

-Patients involved in other related investigations of transfusion practices.

-Patients with diagnosis of pneumonia within the first 48 hours of admission to ICU. (Community acquired pneumonia or nosocomial pneumonia).

\section{Techniques and procedures}

The study will appear to the committee of ethics and investigation of the Instituto de Ciencias of Salud (CES), 
the financial entities to define and each institution that requires it. Then we will present to the National Network of Investigation in Mechanical Ventilation that includes ICU of Medellín, Bogota, Cali and Barranquilla.

Once the inclusion criteria are fulfilled, the patients will be followed up for 30 days, hospital discharge or death according to the first occurrence.

All the doctors will be informed about the characteristics of the study, admission criteria, measures of support and the clinical handling of the patients during their ICU stay.

\section{Statistical analysis}

The continuous variables will be expressed as average with their standard deviation and the $t$ Student will be used for the comparison between the averages in both groups. The categorical variables will be expressed as frequency allocations and the test of the chi-square will be used to determine the differences between the frequency allocations in both groups. A univariate analysis will be used and a multivariate logistic regression analysis to fit the independent risk factors for the development of VAP.

The respective relative risks with their corresponding confidence interval (CI) of $95 \%$ will be reported. A p value of $<0.05$ will be considered to determine the statistical significance. The analysis will take control of the statistical program SPSS 13. (Chicago).

\section{Ethical aspects}

The investigation will carry out previous academic and ethical endorsements from CES and other research committees of each of the participating Clinics and Hospitals in the project. In this study the scientific norms, technical and administrative are fulfilled for the investigation in health emanated by the Ministry of Health of Colombia (resolution 8430 of 1993, by which the norms scientific, technical, and administrative settle down for the investigation in health). The investigation is based on solid scientific knowledge and it is executed by suitable medical personnel with experience in the handling of patients with this pathology.

\section{Discussion}

The patients in the intensive care frequently are coming anemic, the etiology of this is the poor availability of iron and medullar depression by cytoquines [1], however the real impact of maintaining a good level of hematocrit in the intensive care patients is questionable, Hebert and colls in a previous trials demonstrated that a conservative management of transfusions is equal effective than a more liberal management [5].
The immunosuppressant effects of transfusion is not really studied, there are many studies that tried to made a relation between transfusion and infectious complications as a consequence of the immunosuppressant effects, Andrew Shorr and Colls as a results of a secondary analysis of the Crit study demonstrated a possible relation between ventilator associated pneumonia and transfusions[13].

Ventilator associated pneumonia constitute a primary problem in the actual management of patients in intensive care units, associated with important morbidity and attributable mortality $[15,16]$ multiple risk factors had been associated with its presence[16].

We design a multi center prospective cohort study in multiple intensive care units in Colombia, we will follow for thirty days, patients in mechanical ventilation who do not have initial diagnosis of pneumonia.

We will describe all variables associated with pneumonia and transfusions and then after an unvaried analysis and a logistic regression analysis we will establish a really association between transfusion and pneumonia and all other factors associated with this.

Several risk factors have been associated with the occurrence of ventilator associated pneumonia, we will establish the really presence of this factors and the possible association between transfusion and ventilator associated pneumonia, also we will describe the transfusion policies in our intensive care units and the possible relation with other nosocomial infections.

\section{Conclusion}

This is a multi center cohort study in various intensive care unit in Colombia, we will try to demonstrated as a first end point the association between pneumonia and transfusion, and all other risk factors associated with this, also we will establish the incidence of ventilator associated pneumonia and the main epidemiological factors, establish the incidence of anemia in mechanical ventilated patients and the current transfusion practice in our media.

\section{Competing interests}

The author(s) declare that they have no competing interests.

\section{Authors' contributions}

DY and BJ conceived the study, participated in its design, coordinated the study and drafted the manuscript, $\mathrm{OH}$, $\mathrm{RM}, \mathrm{MG}$ participated in the design, JPV participated in the recollection of patients. All authors read and approved the final manuscript. 


\section{Acknowledgements}

Supported by Susalud (Compañía suramericana de servicios de salud SA) and by the CIDI (Centro de investigaciones integradas).

\section{References}

I. Krafte-Jacobs B: Anemia of critical illness and erythropoietin deficiency. Intensive care Med 1997, 23: | 37-I38.

2. Vincent JL, Baron JF, Reinhart K, Gattinoni L, Thijs L, Webb A, Meier Hellman A, Nollet G, Peres-Bota D, ABC (Anemia and Blood transfusion in critical care) investigators: Anemia and blood transfusion in critically ill patients. JAMA 2002, 288: |499-I 507.

3. Wilkerson DK, Rosen AL, Sehgal LR, Gould SA, Sehgal HL, Moss GS: Limits of cardiac compensation in anemic baboons. Surgery 1988, I 03:665-670.

4. Leung JM, Weiskopf RB, Feiner J, Hopf HW, Kelley S, Viele M, Lieberman J, Watson J, Noorani M, Pastor D, Yeap H, Ho R, Toy P: Electrocardiographic ST segment changes during acute, severe isovolemic hemodilution in humans. Anesthesiology 2000, 93:1004-10

5. Hebert PC, Wells G, Tweeddale M, Martin C, Marshall J, Pham B, Blajchman M, Schweitzer I, Pagliarello G: Does transfusion practice affect mortality in critically ill patients? Am J Respir Crit Care Med 1997, 155:1618-1623.

6. Dodd RY, Notari EP 4th, Stramer SL: Current prevalence and incidence of infectious disease markers and estimated window-period risk in the American Red Cross blood donor population. Transfusion 2002, 42:975-979.

7. Sazama K: Reports of $\mathbf{3 5 5}$ transfusion-associated deaths: $\mathbf{1 9 7 6}$ through 1985. Transfusion 1990, 30:583-590.

8. Silliman CC, Boshkov LK, Mehdizadehkashi Z, Elzi DJ, Dickey WO, Podlosky L, Clark G, Ambruso DR: Transfusion-related acute lung injury: epidemiology and a prospective analysis of etiologic factors. Blood 2003, I 0 I:454-462.

9. Taylor RW, Manganaro L, O'Brien J, Trottier SI, Parkar N, Veremakis $C$ : Impact of allogenic packed red blood cell transfusion on nosocomial infection rates in the critically ill patient. Crit Care Med 2002, 30:2249-2254.

10. Sho M, Sandner SE, Najafian N, Salama AD, Dong V, Yamada A, Kishimoto K, Harada H, Schmitt I, Sayegh MH: New insights into the interactions between $\mathrm{T}$-cell costimulatory blockade and conventional immunosuppressive drugs. Ann Surg 2002 , 236:667-675.

II. Mincheff MS, Meryman HT, Kapoor V, Alsop P, Wotzel M: Blood transfusion and immunomodulation: a possible mechanism. Vox Sang 1993, 65:18-24.

12. Talbot TR, D'Agata EM, Brinsko V, Lee B, Speroff T, Shaffner W: Perioperative Blood Transfusion Is Predictive of Poststernotomy Surgical Site Infection: Marker for Morbidity or True Immunosuppressant? Clinical Infectious Diseases 2004, 38: $1378-1382$

13. Shorr AF, Duh MS, Kelly KM, Kollef MH, CRIT Study Group: Red blood cell transfusion and ventilator-associated pneumonia: A potential link? Crit Care Med 2004, 32:666-674.

14. Vincent JL, Bihari DJ, Suter PM, Bruining HA, White J, Nicolas-Chanoin $\mathrm{MH}$, Wolff $M$, Spencer RC, Hemmer M: The prevalence of nosocomial infection in intensive care units in Europe. Results of the European Prevalence of Infection in Intensive Care (EPIC) Study. EPIC International Advisory Committee. JAMA 1995, 274:639-644.

15. Heyland DK, Cook DJ, Griffith L, Keenan SP, Brun-Buisson C: The attributable morbidity and mortality of ventilator-associated pneumonia in the critically ill patient. The Canadian Critical Trials Group. Am J Respir Crit Care Med 1999, I 59:1249-1256.

16. Chastre J, Fagon JY: Ventilator-associated pneumonia. Am J Respir Crit Care Med 2002, I 65:867-903.

17. Papazian L, Bregeon F, Thirion X, Gregoire R, Saux P, Denis JP, Perin G, Charrel J, Dumon JF, Affray JP, Gouin F: Effect of ventilatorassociated pneumonia on mortality and morbidity. Am Respir Crit Care Med 1996, 1 54:91-97.

18. Rello J, Ollendorf DA, Oster G, Vera Llonch M, Bellm L, Redman R, Kollef $\mathrm{MH}$, Outcomes Scientific Advisory Group: Epidemiology and outcomes of ventilator-associated pneumonia in a large US database. Chest 2002, I 22:2 I| 15-2I 2 I.
19. Warren DK, Shukla SJ, Olsen MA, Kollef MH, Hollenbeak CS, Cox MJ, Cohen MM, Fraser VJ: The outcome and attributable cost of ventilador associated pneumonia among intensive care unit patients in a suburban medical center. Crit Care Med 2003, 3 I: I3 I2- I I37.

20. Cook DJ, Kollef $\mathrm{MH}$ : Risk factors for ICU acquired pneumonia. JAMA 1998, 279:I605-I606.

21. Corwin HL, Gettinger A, Pearl RG, Fink MP, Levy MM, Abraham E, Maclntyre NR, Shabot MM, Duh MS, Shapiro MJ: Anemia and blood transfusion in the critically ill: Current clinical practice in the United States: The CRIT study. Crit Care Med 2004, 32:39-52.

22. Blajchman MA, Dzik S, Vamvakas EC, Sweeney J, Snyder EL: Clinica and molecular basis of transfusion induced immunomodulation: summary of the proceedings of a state-of-the-art conference. Transfus Med Rev 200 I, I 5: 108-I35.

23. Vamvakas EC: Transfusion-associated cancer recurrence and postoperative infection: Meta-analysis of randomized, controlled clinical trials. Transfusion 1996, 36:175-186.

24. Tang R, Chen HH, Wang YL, Changchien CR, Chen JS, Hsu KC, Chiang JM, Wang JY: Risk factors for surgical site infection after elective resection of the colon and rectum: $A$ single-center prospective study of $\mathbf{2 , 8 0 9}$ consecutive patients. Ann Surg 2001, 234:181-189.

25. Duggan J, O'Connell D, Heller R, Gosh H: Causes of hospitalacquired septicaemia: A case control study. Q J Med 1993 , 86:479-483.

26. Shorr AF, Jackson WL, Nelly KM, Fu M, Kollef MH: Transfusion Practice and Blood Stream Infections in Critically III Patients. Chest 2005, I 27:1722-1728.

27. Hebert PC, Wells G, Blajchman MA, Marshall J, Martin C, Pagliarello G, Tweedale M, Schweitzer I, Yetisir E: A multicenter, randomized, controlled clinical trial of transfusion requirements in critical care. Transfusion Requirements in Critical Care Investigators, Canadian Critical Care Trials Group. N Engl J Med 1999, 340:409-417

28. Joseph L, Fleiss : Statistical Methods for Rates and Proportions. 2nd edition. John Wiley \& Sons; 198I:44-45. ISBN 0-47|-06428-9

29. Pingleton SK, Fagon JY, Leeper KV Jr: Patient selection for clinical investigation of ventilator-associated pneumonia: Criteria for evaluating diagnostic techniques. Chest 1992 , 1 02:553S-556S

30. Pugin J, Auckenthaler R, Mili N, Janssens JP, Lew PD, Sutter PM: Diagnosis of ventilator-associated pneumonia by bacteriologic analysis of bronchoscopic and nonbronchoscopic "blind" bronchoalveolar lavage fluid. Am Rev Respir Dis 1991, |43: I |2|- | |29.

31. Fartoukh M, Maitre B, Honore S, Cerf C, Zahar JR, Brun-Buisson C: Diagnosing pneumonia during mechanical ventilation: The clinical pulmonary infection score revisited. Am J Respir Crit Care Med 2003, 168:173-179.

32. Vincent JL, Moreno R, Takala J, Willatts S, De Mendonca A, Bruining H, Reinhart CK, Suter PM, Thijs LG: The SOFA (Sepsis-related Organ Failure Assessment) score to describe organ dysfunction/failure. On behalf of the Working Group on SepsisRelated Problems of the European Society of Intensive Care Medicine. Intensive Care Med 1996, 22:707-710.

33. Knaus WA, Draper EA, Wagner DP, Zimmerman JE: APACHE II: A severity of disease classification system. Crit Care Med 1985, I3:8|8-829.

\section{Pre-publication history}

The pre-publication history for this paper can be accessed here:

http://www.biomedcentral.com/1471-2466/6/18/prepub 